\title{
Transição para o ensino superior: aspiração dos alunos do ensino médio de uma escola pública ${ }^{1}$
}

\section{Transition to higher education: aspirations of high school students from a public school}

\author{
Maria José Braga ${ }^{2}$ \\ Flavia Pereira Xavier ${ }^{2}$
}

\begin{abstract}
RESUMO
O trabalho discute resultados de uma pesquisa que identifica e analisa projetos e aspirações de continuidade dos estudos de alunos do ensino médio de uma escola estadual da região metropolitana de Belo Horizonte, Minas Gerais. Busca-se compreender as formas de presença da escola e da família na elaboração dos projetos de vida. A discussão se baseia nos dados coletados por meio de questionários autoaplicados dirigidos aos alunos. Foram realizados cruzamentos entre a variável resposta (se o aluno pretende cursar o ensino superior) e as variáveis relacionadas às características adscritivas dos alunos, à trajetória escolar, ao contexto familiar e escolar. A partir dos cruzamentos, foram selecionadas as variáveis que indicavam associação com a variável resposta e estimado um modelo de regressão logística que buscou analisar os fatores associados às aspirações dos alunos em cursar o ensino superior. Os achados indicaram que três características distinguem mais os alunos em termos de aspirações de continuidade de estudos: sexo, renda familiar e incentivo da família.
\end{abstract}

Palavras-chave: projetos de vida; aspirações escolares; ensino médio; ensino superior; escola pública.

DOI: $10.1590 / 0104-4060.46817$

1 Pesquisa financiada pela Fundação de Amparo à Pesquisa do Estado de Minas Gerais (Fapemig).

2 Universidade Federal de Minas Gerais. Faculdade de Educação. Belo Horizonte, Minas Gerais, Brasil. Av. Pres. Antônio Carlos, nº6627. Pampulha. CEP: 31270-901.E-mails: mj.braga@ terra.com.bre flaviapx@yahoo.com.br 


\begin{abstract}
This paper discusses the results of a research that identifies and analyses projects and aspirations of the high school students from a state school located at the metropolitan region of Belo Horizonte, Minas Gerais, regarding the continuation of their studies. We search to understand the ways in which school and families are present in the elaboration of the life projects. The discussion is based on data gathered through self-applied questionnaires taken by the students. We crossed the answer variable (whether the student intends to attend higher education) and variables related to ascription characteristics of the students, to their school trajectory, and to their family and school context. Based on the crossings, we selected the variables that indicated association with the answer variable and a model of logistic regression was estimated that intended to analyze the factors associated with the expectations of students to attend higher education. The findings indicated three characteristics that most distinguish the students in terms of aspirations of continuing their education: gender, family income and family support.
\end{abstract}

Keywords: life projects; school aspirations; high school; higher education; public school.

\title{
Introdução
}

Este trabalho apresenta parte dos resultados de uma pesquisa que buscou identificar e analisar projetos e aspirações de continuidade dos estudos de alunos do ensino médio de uma escola estadual da região metropolitana de Belo Horizonte, MG. A pesquisa se desenvolveu em dois momentos. O primeiro trabalhou com dados de um questionário que buscou identificar elementos do cenário sociodemográfico, familiar e escolar dos alunos investigados. O segundo momento visou o aprofundamento, por meio de grupos focais, de questões apontadas pelos dados do questionário. Neste artigo, discutem-se especificamente os resultados da etapa quantitativa da pesquisa, na qual foram investigados fatores que estão associados às aspirações dos alunos de ingressar no ensino superior.

$\mathrm{O}$ interesse de pesquisar os projetos de futuro dos jovens se justifica, sobretudo, porque o período do ensino médio, cobrindo uma etapa da vida que coincide com a adolescência e a juventude ${ }^{3}$, coincide com um momento ligado à transição para a vida adulta (trabalho, ensino superior, casamento, etc). Nesse

3 Embora o objeto desta pesquisa faça fronteira com os estudos sobre juventude, não vamos nos debruçar sobre uma revisão de literatura sobre essa temática. 
sentido, o ensino médio não seria apenas o momento de continuidade do ensino fundamental e de preparação para o ensino superior, mas também de elaboração de projetos fundamentais de transição para o futuro em suas diferentes dimensões.

O foco deste trabalho recai sobre a transição específica do ensino médio para o ensino superior/continuidade dos estudos. A problemática mais geral da pesquisa e a análise dos dados se apoiam: por um lado, no pressuposto da centralidade dos projetos de vida na faixa etária dos alunos do ensino médio, situados no contexto mais abrangente de transição para a vida adulta e, ao mesmo tempo, na relação desses jovens com o tempo futuro e; por outro lado, nos estudos sobre as relações entre a escola e as famílias, particularmente as populares.

\section{A construção de projetos e aspirações de continuidade dos estudos, tipos de relação com o tempo futuro e as relações entre as famílias populares e a escola}

Quando tratamos do curso da vida social, “[...] a nível das representações, continuam a persistir normatividades etárias, isto é, idades consideradas ideais para se darem determinados passos". (PAIS, 2009, p. 381). O ensino médio não seria o momento apenas de continuidade do ensino fundamental e de preparação para o ensino superior, mas também de elaboração de projetos fundamentais de transição para o futuro. Essas transições podem se constituir em ritos de passagem - quando marcadoras da transição para a vida adulta - ou, conforme Pais (2009), em algumas circunstâncias, em ritos de impasse. Nesse caso, o autor afirma que "[...] são mais fluidos e descontínuos os traços que delimitam as fronteiras entre as diferentes fases da vida". (PAIS, 2009, p. 373).

Para abordar a elaboração de projetos e expectativas de futuro por parte dos alunos do ensino médio, entendemos ser importante discutir o tema da relação do sujeito com o tempo, mais especificamente, com o futuro. (MERCURE, 1995; LECCARDI, 2005; CHARLOT, 1999).

A noção de horizonte temporal, portanto, se apresenta como pertinente para a compreensão do problema colocado neste trabalho. "O campo de projetos, de planificações, de previsões e de visões antecipadas, de expectativas e esperanças", constitui o cenário básico dessa noção. (MERCURE, 1995, p. 20-21).

Leccardi (2005) desenvolve uma reflexão sobre a relação com o tempo que, em alguns aspectos, se aproxima da de Mercure (1995). A reflexão da primeira autora foca, inicialmente, em tipos de relação com o futuro, individual e coletiva, que predominam na modernidade, contextualizando-os historicamente 
em uma primeira modernidade e em uma modernidade contemporânea. Para essa análise, a autora não foca em clivagens sociais, étnicas e de gênero, apenas aponta a existência de seu impacto na individualização das biografias, de uma maneira mais universal. Em segundo lugar, a autora focaliza as novas tendências de temporalização para os jovens.

A modernidade contemporânea, segundo Leccardi (2005), possui um componente de incerteza: os imediatismos, assim como as vivências contingentes, tendem a dominar o cenário. Torna-se pouco sensato pensar e investir em projetos de longo prazo e, mais ainda, adiar satisfações. $\mathrm{O}$ tempo presente passa a ser o referente central para o indivíduo singular e coletivo.

Hoje, segundo Melucci (1997), um percurso previsível para o ingresso na vida adulta constitui exceção. Identifica-se uma ausência de etapas tradicionais, previsíveis, normativas: conclusão dos estudos, inserção no trabalho, independência de moradia, casamento, filhos. Assiste-se a uma desinstitucionalização da vida, ou seja, as instituições estão presentes nas biografias, mas deixaram de ser base da continuidade biográfica.

Ainda segundo Leccardi (2005), apesar do quadro acima descrito, percebem-se diferenciações nas atitudes de autodeterminação nas escolhas e utilização de estratégias pelos sujeitos, conforme o impacto das clivagens sociais, étnicas e de gênero. Assim, mesmo que o futuro se configure como incerto, inseguro, contingente, há casos de não absolutização do presente imediato e onde se identifica uma "[...] habilidade de manter uma direção ou trajetória, a despeito da impossibilidade de prever seu destino final". (LECCARDI, 2005, p. 9).

Alguns jovens lidam positivamente com a imprevisibilidade, embora estes constituam uma pequena parcela culturalmente dominante. Esse controle sobre o tempo significa antes de tudo uma vontade de atingir objetivos, que pressupõe a posse de determinados recursos culturais, sociais e econômicos. A maioria dos jovens que têm um futuro fora de controle e um presente estendido como referência principal - um presente sem fascínio - elabora projetos de curto ou curtíssimo prazo. Esses projetos curtos constituem uma terceira via "[...] entre a capacidade especial de gestão da complexidade [...] e a referência exclusiva ao presente daqueles que não conseguem construir reações adequadas diante do crescimento da indeterminação do futuro". (LECCARDI, 2005, p. 10).

Charlot (1999), analisando dados empíricos de sua investigação sobre a relação com o saber de jovens de liceus populares na França, oferece contribuições importantes para a discussão que aqui se trava. Para alguns dos jovens investigados existe um curso normal do tempo, uma rotina da vida, uma sucessão cronológica do tempo: “[...] se é criança, tenta-se aproveitar a juventude e, ao mesmo tempo, vence nos estudos; obtêm-se diplomas, encontra-se um trabalho; casa-se, tem-se filhos”. (CHARLOT, 1999, p. 56). Esses jovens inscrevem seus projetos 
no tempo longo de uma vida normal, que inclui a geração dos próprios filhos. No entanto, essa vida normal não está assegurada para os jovens das camadas populares, segundo o autor. Para eles, o curso da construção da vida, no tempo, pode ser perturbado e, muitas vezes, interrompido, para melhor ou para pior; a vida pode balançar em função de um episódio - ligado à família, ao trabalho, à escola, à religião, à droga - a partir do qual há um antes e um depois. O tempo da vida pode ser atravessado por rupturas que desorganizam o curso normal da vida.

Já no que tange à relação da escola com a família, assiste-se nos dias atuais a emergência de um novo fenômeno social, de forte visibilidade: o do apelo de aproximação e parceria entre a escola e a família. Pode-se afirmar a existência de um consenso social, acerca da necessidade dessa aproximação. Esses apelos constituem tendências, não só brasileiras, mas também mundiais. (NOGUEIRA, 2006).

Uma explicação para essa busca de aproximação, do lado da família, estaria na tentativa de superação dos problemas de desempenho, de comportamento, de absenteísmo e repetência escolares - no limite, do abandono/evasão da escola problemas que estariam mais presentes na escolarização dos alunos dos meios populares. Diogo (2010) indaga se haveria um impacto real do envolvimento dos pais no sucesso escolar dos filhos. De fato, as pesquisas o apontam, a parceria, a cooperação entre e escola e família são muitas vezes permeadas de conflitos e tensões. A falta de sintonia é mais acentuada com as famílias populares, uma vez que elas são menos equipadas, sobretudo de recursos culturais, para dialogar com a escola. Assim, a relação entre famílias populares e escola tem sido tensa, contraditória, "armadilhada", apesar da demanda bilateral de parceria. (SILVA, 2003).

As famílias dos meios populares tenderiam a investir menos na escolarização dos filhos, reconhecendo que são reduzidas suas chances de êxito escolar, assim como de mobilidade social ascendente via escola, dada a ausência de capital cultural como herança a transmitir para os filhos. (BOURDIEU, 1998). Estes últimos podem sofrer, ainda, consequências desfavoráveis em sua escolarização pelo fato de serem socializados em modos de socialização conflitantes com os da escola. (THIN, 2006).

\section{Metodologia}

\section{Dados}

A discussão se baseia nos dados coletados, por meio de questionários autoaplicados, dos alunos de uma escola pública da Região Metropolitana de Belo Horizonte. Trata-se de uma escola pública estadual, estabelecimento 
tradicional e que atualmente atende cerca de 1.300 alunos. Oferece as séries finais do ensino fundamental e o ensino médio, sendo que este é oferecido nos turnos matutino e noturno.

O questionário foi composto por 34 questões, nas quais foram investigadas as características sociodemográficas dos alunos, sua trajetória escolar e sua aspiração de conclusão do ensino médio e de ingresso no ensino superior. Responderam ao questionário os alunos que estavam presentes no dia da aplicação do instrumento. Os dias para aplicação foram previamente combinados com a direção da escola que comunicou aos professores que cederam um horário para tal. O tempo médio gasto pelos alunos para preenchimento do questionário foi cerca de 18 minutos.

A aplicação ocorreu em todas as turmas do ensino médio da escola (14 turmas) nos meses de maio, agosto e outubro de 2014. Destaca-se que a escola vem paulatinamente adotando a política de "diuturnização" do ensino médio. Em 2014, havia apenas uma turma da $2^{\mathrm{a}}$ série e uma turma da $3^{\mathrm{a}}$ série no noturno.

Vale ressaltar que 370 alunos responderam ao questionário, o que corresponde a cerca de $75 \%$ do total de alunos que constavam nas listas de presença fornecidas pela direção da escola. Já em maio, como mencionado pela própria direção, muitos alunos já estavam infrequentes. É muito provável que a variação de perfis entre os alunos tenha sido afetada. Trataremos as informações coletadas como um retrato da aspiração dos jovens que estão frequentando o ensino médio nesta escola em ingressar no ensino superior. Na verdade, pode-se ter um viés de seleção, uma vez que os alunos infrequentes podem possuir características sociodemográficas e culturais distintas dos alunos que permaneceram frequentes. Mas este viés é comum nas pesquisas em que as amostras não são domiciliares.

Dos alunos listados nas folhas de presença 225 (46\%) eram do sexo masculino e 264 (54\%) do sexo feminino, distribuição que segue o mesmo padrão da distribuição das matrículas no ensino médio por gênero contabilizadas pelo Censo Escolar ${ }^{4}$. Já entre os respondentes 156 (42,2\%) são do sexo masculino e $212(57,3 \%)$ do sexo feminino.

\section{Variáveis}

A variável de interesse é a aspiração do aluno em cursar o ensino superior. Esta é uma variável binária, cujas categorias são: (0) o aluno não pretende fazer o curso superior e (1) o aluno pretende fazer o curso superior.

4 A proporção das matrículas no ensino médio por sexo dos alunos pode ser calculada a partir dos dados agregados do Censo Escolar na Sinopse Estatística da Educação Básica de 2013, última edição da sinopse disponível. $47 \%$ dos matriculados são meninos e $53 \%$, meninas. As sinopses estão disponíveis para download em $<$ http://portal.inep.gov.br/basica-censo-escolar-sinopse-sinopse>. 
São consideradas como características adscritivas dos alunos o sexo e a cor. A cor/raça dos alunos segue o padrão de autodeclaração e originalmente a questão possuía as seguintes opções de respostas: (1) Branco; (2) Preto; (3) Pardo; (4) Amarelo (origem oriental); (5) Indígena ou; (6) Não deseja declarar. Apenas 18 alunos assinalaram uma das três últimas categorias. Portanto, para as análises multivariadas, foram considerados apenas os alunos que se autodeclararam brancos e negros (pretos e pardos).

Considerou-se como variáveis do contexto familiar: a escolaridade dos pais, a renda familiar, a importância dada pela família ao ensino superior e a percepção do aluno sobre as condições financeiras da família para ajudá-lo a cursar o ensino superior. Para os propósitos deste artigo, a escolaridade do pai e da mãe do aluno foi tratada como um indicador de capital cultural. A operacionalização desse indicador foi realizada por meio de análise fatorial das duas variáveis de escolaridade. (HAIR JR. et al., 2009). O fator resultante da análise explica $67,85 \%$ da variação total. Para tornar o fator mais interpretável a escala original em desvios-padrão foi agrupada em três categorias: mais baixo, médio e mais alto. $\mathrm{O}$ agrupamento foi realizado por meio da análise de cluster pelo método de agrupamento não hierárquico designado $k$-means. O cluster, nesse caso, equivale a um conjunto de perfis de capital cultural no qual cada perfil está mais próximo ao centroide que define o cluster do que dos centroides de quaisquer outros clusters. (PESTANA; GAGEIRO, 2005; HAIR JR. et al., 2009).

A renda familiar é tratada em faixas de salário mínimo, fixados no salário de 2014, ano da aplicação dos questionários: até 2 salários mínimos, mais de 2 a 5 salários mínimos e mais de 5 salários mínimos 5 .

A percepção do aluno sobre as condições econômicas da família é tratada como uma variável binária, embora a questão tivesse quatro categorias originalmente: (1) podem facilmente me ajudar; (2) podem me ajudar, mas com algum sacrifício; (3) não podem me ajudar ou; (4) eu tenho que trabalhar para ajudar minha família. As opções 1 e 2 foram recodificadas numa única categoria, assim como também foram agrupadas as categorias 3 e 4. Isso ocorreu em função da baixa frequência de respondentes, principalmente, nas categorias 1 e 2 .

A questão sobre a importância dada pela família ao ensino superior foi aplicada com três categorias: (1) Sim, (2) Não ou (3) Não se fala desse assunto na minha família. As categorias 2 e 3 foram agrupadas devido à baixa frequência

5 Em Minas Gerais, segundo o Censo Demográfico de 2010, a renda de 37,4\% dos domicílios estava neste mesmo intervalo. O perfil econômico dos alunos corresponde ao encontrado na população em geral. Este dado do censo demográfico pode ser calculado a partir das informações disponíveis em $<$ http://www.sidra.ibge.gov.br/bda/popul/default.asp?t=1\&z=t\&o=25\&u1=1\&u2= $1 \& u 3=1 \& u 4=1 \& u 5=1 \& u 6=1>$. 
de alunos que assinalaram estas opções de resposta. Assim, a questão foi tratada como uma variável binária.

A trajetória do aluno foi mensurada pela questão relativa à rede de ensino que o aluno estudou durante o ensino fundamental e pela reprovação do aluno (no ensino fundamental e/ou médio).

Como contexto da escola foram consideradas duas variáveis: se os colegas do aluno pretendem fazer o curso superior e se os professores encorajam o aluno a cursar o ensino superior. Ambas são binárias.

Em uma etapa preliminar outras variáveis foram consideradas, tais como, se o aluno trabalha, a ocupação dos pais, número de irmãos, dentre outras. Essas variáveis apresentaram baixa variação de respostas. Como se trata de um estudo de caso, a população investigada possui características bastante semelhantes, tornando algumas variáveis pouco discriminantes, mesmo que elas usualmente possam distinguir bem alguns grupos sociais em pesquisas com grandes amostras.

\section{Procedimentos de análise}

Foram realizados cruzamentos entre a variável resposta (se o aluno pretende cursar o ensino superior) e as variáveis destacadas na seção anterior. Foi realizado também o Teste do Qui-quadrado para independência $\left(X^{2}\right)$ para cada cruzamento. $\mathrm{O}$ teste avalia se existe uma relação estatisticamente significativa entre as variáveis categóricas. A hipótese nula é de que as variáveis não estão associadas, em outras palavras, são independentes. Ressalta-se que o teste não foi realizado para os pares de variáveis que possuíam frequência esperada por células menor que 5. Alternativamente, para as situações em que este pressuposto do teste do Qui-quadrado foi violado, o Teste Exato de Fisher foi calculado ${ }^{6}$. O Teste de Fisher se aplica às tabelas $2 \mathrm{X} 2$, para os casos em que os pressupostos do Teste do Qui-quadrado foram violados.

A partir dos cruzamentos, foram selecionadas as variáveis que indicavam associação com a variável resposta e estimado um modelo de regressão logística (MENARD, 2001) que buscou analisar os fatores associados às aspirações dos alunos em cursar o ensino superior.

6 São pressupostos do Teste do Qui-quadrado: 1) os dados são selecionados aleatoriamente; 2) todas as frequências esperadas são maiores do que ou igual a 1 e; 3) não mais de $20 \%$ das frequências esperadas são inferiores a 5 . Nas tabelas de contingência $2 \times 2$, os valores esperados menores que 5 e amostras pequenas podem afetar a aproximação da distribuição, Qui-quadrado da estatística do teste fazendo com que ela não seja suficientemente boa. 


\section{Resultados}

A Tabela 1 mostra a distribuição dos alunos segundo as aspirações de cursar o ensino superior pelas variáveis de características adscritivas, do contexto familiar, trajetória escolar e do contexto escolar. Para cada cruzamento também é reportado o coeficiente do Teste do Qui-quadrado e sua respectiva significância ou a significância do Teste Exato de Fisher. Valores da significância (sig.) inferiores a 0,05 são considerados estatisticamente significativos, indicando associação entre cada variável e a aspiração do aluno em cursar o ensino superior.

Considerando as características adscritivas analisadas, a relação entre o sexo e as aspirações foi significativa pelo Teste do Qui-quadrado, com vantagem para as meninas. Já a diferença na distribuição entre brancos e negros não foi estatisticamente significativa, ou seja, para a população analisada não há associação entre cor e pretensão de ingresso no ensino superior. Isso ocorre pela homogeneidade dos alunos da escola neste quesito.

Considerando as variáveis relacionadas ao contexto da família dos alunos, observa-se que, embora a maioria dos alunos pretenda cursar o ensino superior, estes estão mais concentrados dentre aquelas famílias que possuem capital cultural mais alto, renda mais alta, que consideram importante que o aluno curse o ensino superior e aquelas que possuem condições econômicas para ajudar o aluno a cursar o ensino superior. Os resultados dos testes indicam que cada uma das variáveis possui uma relação estatisticamente significativa com as aspirações dos alunos.

Não foi possível calcular nem o Qui-quadrado nem o Teste Exato de Fisher para o cruzamento entre rede de ensino e aspiração do aluno. Isso ocorreu porque o perfil dos alunos é muito semelhante. Pela distribuição percentual é possível ver uma diferença entre aqueles que disseram que estudaram na rede pública e aqueles que estudaram todo o ensino fundamental na rede privada. Mas como nenhum teste de associação pode ser calculado, como explicitado na seção metodológica, empiricamente não podemos afirmar que essa diferença é significativa, ou seja, que haja uma associação entre as variáveis.

Para o cruzamento entre reprovação e aspiração, a distribuição dos percentuais indica que os alunos que nunca reprovaram são aqueles também que mais disseram que pretendem cursar o ensino superior $(88,6 \%)$. Contudo, o Teste Exato de Fisher não foi significativo, indicando que, para a população estudada, não podemos afirmar que as variáveis estejam associadas.

Considerando o contexto da escola, para o cruzamento da variável "Se os colegas do aluno pretendem fazer o curso superior" com a aspiração do aluno 
observa-se que $90,7 \%$ dos alunos que disseram que os colegas pretendem ingressar na universidade também o desejam. Entretanto, não há uma associação estatisticamente significativa entre as variáveis. Isso ocorre porque há poucos alunos que disseram que os colegas pretendem fazer o curso superior, mas que eles não pretendem.

Do mesmo modo, para o cruzamento entre as variáveis "Os professores encorajam o aluno a cursar o ensino superior" e aspirações de cursar o ensino superior, o teste não foi estatisticamente significativo.

Como ressaltado, o Teste do Qui-quadrado é muito sensível ao tamanho da amostra e à frequência esperada de casos em cada célula da tabela cruzada. Muitas células apresentaram poucos casos (inferior a cinco). Isso ocorre porque a população pesquisada apresenta certa homogeneidade: são alunos de uma mesma escola, de uma mesma etapa de ensino e que estavam frequentando a escola. Portanto, associações entre variáveis que seriam verificadas com uma amostra com maior variabilidade não são identificadas com a população da pesquisa.

Por fim, vale destacar que embora um teste não tenha sido produzido (o cruzamento entre rede de ensino e aspiração do aluno) e outros não tenham sido significativos, a distribuição das variáveis está na direção esperada com base nos estudos em sociologia da educação. (PORTES, 1993; PIOTTO, 2007). Alunos cujas famílias possuem capital cultural e renda mais elevados, cujos pais podem ajudá-los economicamente a cursar a universidade, que consideram importante cursar a universidade, alunos que estudaram integralmente ou parte do ensino fundamental na rede privada, que nunca foram reprovados, que seus colegas pretendem ingressar no ensino superior e que têm professores que os incentivam a fazer um curso superior, as meninas e os brancos são aqueles alunos mais prováveis de terem aspirações de continuidade de estudos após o ensino médio. São os suspeitos habituais.

As variáveis que constam na Tabela 1 que apresentaram associação com as aspirações dos alunos em cursar o ensino superior foram selecionadas para a etapa de análise multivariada. Nesta estimou-se um modelo de regressão logística binária. A Tabela 2 apresenta os resultados do modelo.

As variáveis referentes ao capital cultural e à percepção do aluno quanto às condições econômicas dos seus pais para ajudá-los a cursar o ensino superior não são estatisticamente significativas. Em outras palavras, na população analisada estas variáveis não afetam as chances de um aluno pretender cursar o ensino superior. Ressalta-se que isso não significa que em amostras maiores e com maior variabilidade este padrão seria o mesmo. Este resultado apenas quer dizer que estas características não discriminam muito bem a população analisada. 
TABELA 1 - DISTRIBUIÇÃO DAS VARIÁVEIS DE CARACTERÍSTICAS ADSCRITIVAS, CONTEXTO FAMILIAR, TRAJETÓRIA E CONTEXTO ESCOLAR POR ASPIRAÇÃO DE CURSAR O ENSINO SUPERIOR

\begin{tabular}{|c|c|c|c|c|}
\hline & & & $\begin{array}{c}\text { Não } \\
\text { pretende } \\
\text { cursar o ES }\end{array}$ & $\begin{array}{c}\text { Pretende } \\
\text { Cursar o } \\
\text { ES }\end{array}$ \\
\hline \multirow{4}{*}{$\begin{array}{l}\text { Caracte- } \\
\text { rísticas } \\
\text { adscri- } \\
\text { tivas }\end{array}$} & & Masculino & $21,9 \%$ & $78,1 \%$ \\
\hline & Sexo & $\begin{array}{l}\text { Feminino } \\
X^{2}=15,528(\text { sig. } 0,000)\end{array}$ & $7,4 \%$ & $92,6 \%$ \\
\hline & & Negros & $14,3 \%$ & $85,7 \%$ \\
\hline & Cor & $\begin{array}{l}\text { Brancos } \\
\left.X^{2}=1,583 \text { (sig. } 0,208\right)\end{array}$ & $9,1 \%$ & $90,9 \%$ \\
\hline \multirow{4}{*}{$\begin{array}{l}\text { Contexto } \\
\text { familiar }\end{array}$} & Capital Cultural & $\begin{array}{l}\text { Mais baixo } \\
\text { Médio } \\
\text { Mais alto } \\
\left.X^{2}=6,73 \text { (sig. } 0,035\right)\end{array}$ & $\begin{array}{l}20,0 \% \\
10,8 \% \\
8,6 \%\end{array}$ & $\begin{array}{l}80,0 \% \\
89,2 \% \\
91,4 \%\end{array}$ \\
\hline & Renda familiar & $\begin{array}{l}\text { Até } 2 \text { SM } \\
\text { Mais de } 2 \text { a } 5 \text { SM } \\
\text { Mais de } 5 \text { SM } \\
X^{2}=7,36 \text { (sig. } 0,025 \text { ) }\end{array}$ & $\begin{array}{c}17,3 \% \\
13,7 \% \\
3,2 \%\end{array}$ & $\begin{array}{l}82,7 \% \\
86,3 \% \\
96,8 \%\end{array}$ \\
\hline & \begin{tabular}{|l|} 
Como aluno considera as \\
condições econômicas dos \\
seus pais para ajudá-lo a \\
cursar o ensino superior
\end{tabular} & $\begin{array}{l}\text { Não podem ajudar } \\
\text { Podem ajudar } \\
X^{2}=11,259(\text { sig. } 0,001)\end{array}$ & $\begin{array}{l}26,7 \% \\
10,5 \%\end{array}$ & $\begin{array}{l}73,3 \% \\
89,5 \%\end{array}$ \\
\hline & \begin{tabular}{|l|} 
Se a família considera \\
importante cursar o ensino \\
superior
\end{tabular} & $\begin{array}{l}\text { Não } \\
\text { Sim } \\
\text { Sig. Teste Exato de Fisher }=0,000^{*}\end{array}$ & $\begin{array}{l}68,8 \% \\
10,7 \%\end{array}$ & $\begin{array}{l}31,3 \% \\
89,3 \%\end{array}$ \\
\hline \multirow[t]{2}{*}{ Trajetória } & $\begin{array}{l}\text { Rede em que cursou a } \\
\text { maior parte do ensino } \\
\text { fundamental }\end{array}$ & $\begin{array}{l}\text { Sempre em escola pública } \\
\text { Sempre em escola particular } \\
\text { Iniciou em escola pública e mudou } \\
\text { para a particular } \\
\text { Iniciou em escola particular e } \\
\text { mudou para a pública } \\
* *\end{array}$ & $\begin{array}{c}15,2 \% \\
11,1 \% \\
0,0 \% \\
0,0 \%\end{array}$ & $\begin{array}{r}84,8 \% \\
88,9 \% \\
100,0 \% \\
100,0 \%\end{array}$ \\
\hline & Reprovação & $\begin{array}{l}\text { Não } \\
\text { Sim } \\
\text { Sig. Teste Exato de Fisher }=0,293^{*}\end{array}$ & $\begin{array}{l}11,4 \% \\
18,8 \%\end{array}$ & $\begin{array}{l}88,6 \% \\
81,3 \%\end{array}$ \\
\hline \multirow{2}{*}{$\begin{array}{l}\text { Contexto } \\
\text { escolar }\end{array}$} & $\begin{array}{l}\text { Se os colegas do aluno } \\
\text { pretendem fazer o curso } \\
\text { superior }\end{array}$ & $\begin{array}{l}\text { Não } \\
\text { Sim } \\
\text { Sig. Teste Exato de Fisher }=0,184^{*}\end{array}$ & $\begin{array}{c}25,0 \% \\
9,3 \%\end{array}$ & $\begin{array}{l}75,0 \% \\
90,7 \%\end{array}$ \\
\hline & $\begin{array}{l}\text { Os professores encorajam } \\
\text { o aluno a cursar o ensino } \\
\text { superior }\end{array}$ & $\begin{array}{l}\text { Não } \\
\text { Sim } \\
\left.X^{2}=0,978 \text { (sig. } 0,323\right)\end{array}$ & $\begin{array}{l}16,9 \% \\
12,2 \%\end{array}$ & $\begin{array}{l}83,1 \% \\
87,8 \%\end{array}$ \\
\hline
\end{tabular}

* 1 célula $(25,0 \%)$ possui frequência esperada inferior a 5 . Nesste caso, o Teste Exato de Fisher foi calculado. $* * 4$ células $(50,0 \%)$ possuem frequência esperada inferior a 5 .

FONTE: As autoras (2016). 
Por outro lado, observa-se que as meninas possuem quase 5 vezes mais chances de pretenderem cursar o ensino superior, quando comparadas aos meninos, independentemente de outras características. Os alunos cujas famílias possuem renda maior que 5 salários mínimos têm 4 vezes mais chances de pretenderem cursar o ensino superior. Por fim, os alunos cujas famílias consideram importante o ensino superior, têm 16 vezes mais chances de pretenderem ingressar na universidade.

TABELA 2 - COEFICIENTES DA REGRESSÃO LOGÍSTICA

\begin{tabular}{l|rrr}
\hline Variáveis & B & Sig. $\begin{array}{c}\text { Razão de } \\
\text { chances }\end{array}$ \\
\hline Sexo (1=feminino) & 1,573 &, 000 & 4,822 \\
Capital Cultural Médio* &, 575 &, 144 & 1,777 \\
Capital Cultural Alto* &, 794 &, 161 & 2,212 \\
Mais de 5 salários mínimos** & 1,405 &, 067 & 4,078 \\
Condições econômicas dos seus pais para ajudá-lo a cursar o &, 505 &, 243 & 1,656 \\
ensino superior (1=podem ajudar) & & & 16,364 \\
$\begin{array}{l}\text { Se a família considera importante cursar o ensino superior } \\
\text { (1=sim) }\end{array}$ & 2,795 &, 000 & \\
Constante & $-2,342$ &, 001 & \\
\hline N = 345 & & & \\
Pseudo R2 = 0,211 & & & \\
\hline
\end{tabular}

* Grupo de referência: Capital Cultural mais baixo.

**Grupo de referência: Até 5 salários mínimos.

FONTE: As autoras (2016).

Para tornar estes efeitos mais interpretáveis, o Gráfico 1 mostra as chances de alguns perfis de alunos. Observa-se que o grupo das meninas cujas famílias têm renda superior a 5 salários e recebem incentivo da família (considera importante cursar o ensino superior) é o grupo com maior vantagem. Opostamente, o grupo em maior desvantagem é composto por meninos cujas famílias têm renda inferior a 5 salários mínimos e não recebem incentivo das suas famílias. 
GRÁFICO 1 - CHANCES DAS ASPIRAÇÕES DE CURSAR O ENSINO SUPERIOR DE PERFIS DE ALUNOS

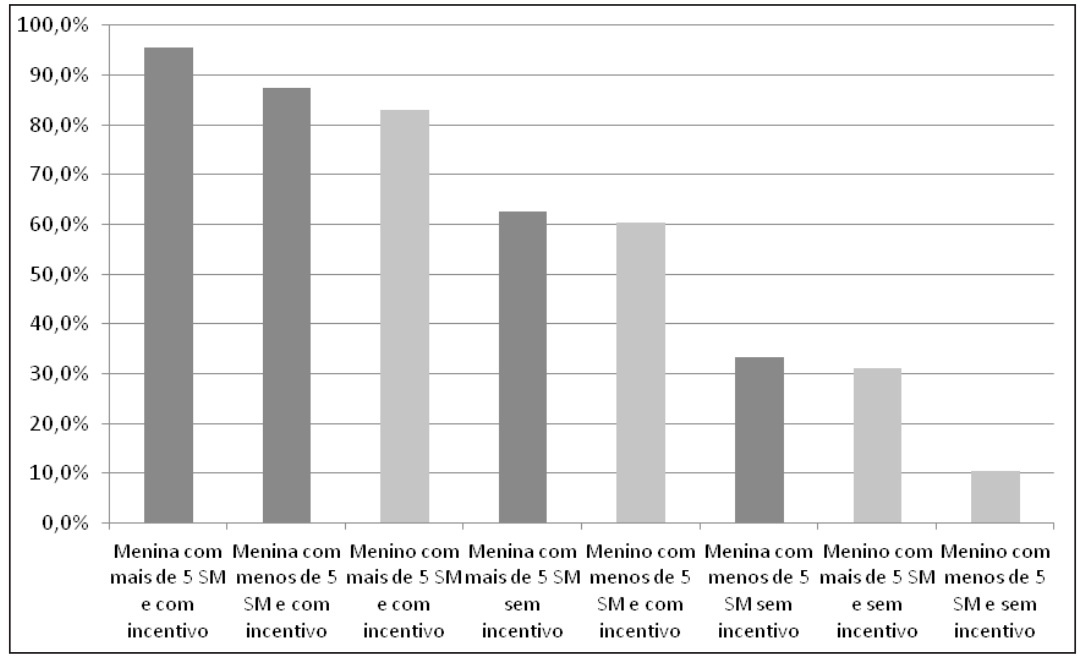

FONTE: As autoras (2016).

\section{Considerações finais}

A título de conclusão, apontamos sumariamente os pontos que seguem.

Em primeiro lugar, encontramos três características dos alunos e suas famílias que ajudam a explicar a construção de projetos de continuidade dos estudos: sexo, renda familiar e incentivo da família. Devemos ressaltar que estas características serviram para discriminar a população estudada, dado que em diversos traços ela é muito homogênea, essencialmente porque todos são alunos de uma mesma escola e da mesma etapa de ensino.

Em segundo lugar, no contexto da família dos alunos, observa-se que, embora a maioria dos alunos pretenda cursar o ensino superior, aqueles cujas famílias possuem renda mais alta e consideram importante que o filho curse o ensino superior são mais prováveis de elaborarem projetos de escolarização prolongada. Os estudos no campo da Sociologia da Educação já apontam de forma consistente esta relação, sobretudo aqueles, entre outros, que abordam o fenômeno da longevidade/sucesso escolar em meios populares. (PORTES, 1993; PIOTTO, 2007). Os recursos econômicos são condições importantes para a rea- 
lização educacional, mas não suficientes. Os resultados mostram que os alunos, cujas famílias consideram importante que eles cursem o ensino superior, têm 16 vezes mais chances de desejarem ingressar na universidade, quando comparados aos colegas que não recebem este tipo de incentivo das suas famílias.

Em terceiro lugar, ressaltamos a questão de gênero. As meninas, como os estudos educacionais têm revelado (CARVALHO, 2003), possuem uma vida escolar mais longeva. Entretanto, essa longevidade não significa que não haja um padrão definido das escolhas pelo curso superior. Ao contrário, elas tendem a escolher cursos que as prepararão para ocupações socialmente menos valorizadas. Foge do escopo desta pesquisa analisar esta questão, embora ela seja relevante.

Por fim, uma questão ligada à discussão teórica da relação com o tempo futuro deve ser ressaltada. As condições objetivas de realização dos projetos dos alunos de camadas populares, o cálculo do provável, os jogam sistematicamente no presente ou no futuro de curto alcance? Pelas evidências da pesquisa quantitativa, tomando as ativas de ingresso no ensino superior como uma dimensão do projeto de futuro, observamos que entre os alunos de camadas populares há algumas características que os fazem possuir aspirações de maior longevidade escolar. Entretanto, não conseguimos compreender se essa aspiração de ingresso no ensino superior é um projeto a ser realizado logo após a conclusão do ensino médio ou é um projeto a ser construído a médio ou longo prazo. Nesse sentido vale lembrar Melucci (1997), que esclarece que as biografias dos alunos de camadas populares tendem mais à experimentação, à provisoriedade, diferentemente de biografias construídas em torno de metas.

Os resultados preliminares da pesquisa com os grupos focais, segunda etapa da pesquisa, ofereceram algumas aproximações a essa indagação. Os alunos consistemente apontaram o desejo de ingressar em um curso técnico e trabalhar antes de ingressar no ensino superior. Esta etapa da escolarização para muitos constituía um horizonte mais distante.

\section{REFERÊNCIAS}

BOURDIEU, P. A escola conservadora: As desigualdades frente à escola e à cultura. In: BOURDIEU, P. Escritos de Educação. Petrópolis: Vozes, 1998. p. 39-64.

CARVALHO, M. P. Sucesso e fracasso escolar: Uma questão de gênero. Educação e Pesquisa, São Paulo, v. 29, n. 1, p. 185-193, jun. 2003. 
CHARLOT, B. Qu'est- que est important pour eux? Qu'est-ce qu'ils attendent? Le rapport au temps. In: CHARLOT, B. Le rapport au savoir en milieu populaire - Une recherche dans les lycées profissionnels de banlieue. Paris: Anthropos, 1999. p. 47-63.

DIOGO, A. M. Do envolvimento dos pais ao sucesso escolar dos filhos: Mitos, críticas e evidências. Revista Luso-Brasileira Sociologia da Educação, n. 1, p. 166-188, 2010.

HAIR JR., J. F.; BLACK, W. C.; BABIN, B. J.; ANDERSON, R. E.; TATHAM, R. L. Análise multivariada de dados. 6. ed. Porto Alegre: Bookman, 2009.

LECCARDI, C. Por um novo significado do futuro: Mudança social, jovens e tempo. Tempo social, v. 1, 17, n. 2, p. 35-57, 2005.

MELUCCI, A. Juventude, tempo e movimentos sociais. Revista Brasileira de Educação, São Paulo, n. 5/6, p. 5-14, 1997.

MENARD, S. W. Applied Logistic Regression Analysis. 2. ed. Thousand Oaks, California: SAGE Publications, 2001. (Quantitative applications in the social sciences: n. 106).

MERCURE, D. Les temporalités sociales. Paris: Éditions L’Harmattan, 1995.

NOGUEIRA, M. A. Família e escola na contemporaneidade: Os meandros de uma relação. Educação \& Realidade, v. 31, n. 2, p. 155-169, 2006.

PAIS, J. M. A juventude como fase de vida: Dos ritos de passagem aos ritos de impasse. Saúde e Sociedade, v. 18, p. 371-381, 2009.

PESTANA, M. H.; GAGEIRO, J. N. Análise de dados para ciências sociais: A complementaridade do SPSS. 4. ed. Lisboa: Silabo, 2005.

PIOTTO, D. C. As exceções e suas regras: Estudantes de camadas populares em uma universidade pública. Tese (Doutorado em Psicologia Escolar e do Desenvolvimento Humano) - Universidade de São Paulo, São Paulo, 2007.

PORTES, É. A. Trajetórias e estratégias escolares do universitário das camadas populares. Dissertação (Mestrado em Educação) - Universidade Federal de Minas Gerais, Belo Horizonte, 1993.

SILVA, P. Escola-família, uma relação armadilhada. Porto: Afrontamento, 2003.

THIN, D. Para uma análise das relações entre famílias populares e escola: Confrontação entre lógicas socializadoras. Revista Brasileira de Educação, v. 11, n. 32, p. 211-225, 2006.

Texto recebido em 18 de maio de 2016. Texto aprovado em 16 de junho de 2016. 
